\title{
An Investigation of the Predictive Speed of the UK VIX for the Downside Risk in European Equity Markets
}

\author{
Chikashi Tsuji ${ }^{1}$ \\ ${ }^{1}$ Faculty of Economics, Chuo University, Japan \\ Correspondence: Chikashi Tsuji, Professor, Faculty of Economics, Chuo University, 742-1 Higashinakano, \\ Hachioji-shi, Tokyo 192-0393, Japan. E-mail: mail_sec_low@minos.ocn.ne.jp
}

Received: September 18, 2018

Accepted: October 25, $2018 \quad$ Online Published: November 2, 2018

doi:10.5539/ibr.v11n12p18

URL: https://dx.doi.org/10.5539/ ibr.v11n12p18

\begin{abstract}
Using the time-series data of UK volatility index (VIX) and other four European equity indices of France, Italy, Spain, and Portugal, and applying quantile regressions, this study investigates the predictive power and predictive speed of the UK VIX for the future sharp price drops in other four European equity markets. As a result, our empirical examinations derive the following findings. (1) First, we clarify that the increases of the UK VIX have statistically significant predictive power for the downside risk in other four European equity markets. (2) Second, our empirical results reveal that the two to four days before, the changes in the UK VIX can forecast the downside risk in other four European equity markets.
\end{abstract}

Keywords: European equity markets, downside risk, quantile regression, VIX

\section{Introduction}

In the fields of business, economics, and finance, downside risk in financial markets is a highly crucial research topic and in fact, recently, many interesting studies regarding this issue have been conducted (e.g., Galsband, 2012; Reboredo and Rivera-Castro, 2014; Min and Kim, 2016; Tsuji, 2017a; Farago and Tédongap, 2018; Bernstein et al., 2018). In a globalizing and tightening international financial markets, how does downside risk in international equity markets spill over? Further, how is the speed of downside risk spillovers in international equity markets? To answer these research questions, by using the time-series data of the UK VIX and other four European equity price indices of France, Italy, Spain, and Portugal, and applying quantile regressions, this study investigates the predictive power and predictive speed of the UK volatility index (VIX) for the future sharp price drops in other European equity markets.

In European equity markets, the UK equity market is particularly important, and the UK VIX used in this study is the volatility index as to the most representative and popular UK equity market index, the FTSE100. Thus, the use of this UK VIX is highly meaningful for conducting beneficial empirical examinations for European equity markets. In addition, the equity markets of France, Italy, Spain, and Portugal are also important in Europe; and all the five countries are included in the Southern and Western Europe. That is, this study focuses on these major important five European equity markets in the Southern and Western Europe.

Furthermore, we stress that this study is highly significant because our study can be expected to reveal the following matters: (1) How does the turmoil of the UK equity market spill over to other European equity markets? (2) Does the increasing fear in the UK equity market predict the downside risk in other European equity markets? The clarifications regarding these matters shall lead to new contributions to existing and future research in the fields of business, economics, and finance; and this is the reason why we conduct this research in this paper. In addition, it is noted that the left-tail downside risk of the price changes in equity markets can be effectively tested by using quantile regressions. More specifically, by applying quantile regressions, we can test the one-to-one linkages between the UK VIX increases and the sharp price drops in other European equity markets more directly. For these reasons, we apply quantile regressions in this study.

As a result, the main findings derived from our investigations are as follows. First, the second and third lags of the changes in the UK VIX predict the downside risk for the French equity market. Next, the second, third, and fourth lags of the changes in the UK VIX predict the downside risk for the Italian equity market. Third, the third and/or fourth lags of the changes in the UK VIX predict the downside risk for the Spanish equity market. Fourth, 
the third and/or fourth lags of the changes in the UK VIX predict the downside risk for the Portuguese equity market. The above results derived from our examinations are interesting and quite new; hence this work makes important and new contributions to the existing and future research in business, economics, and finance.

The rest of this paper is as follows. Section 2 reviews recent literature; Section 3 describes our data and variables; Section 4 introduces our quantitative methodology; Section 5 provides our empirical results; and Section 6 provides our conclusions.

\section{Recent Literature Review}

In this section, we briefly review existing recent literature that studied downside risk of asset prices. We focus on only recent studies in this literature review. First, Hilal et al. (2011) attempted to model the tail dependence between S\&P 500 and US VIX futures, and presented some hedging effectiveness using their model. Further, using the data of emerging economies of Brazil, Chile, Colombia, India, Mexico, Russia, South Africa, and Turkey, and applying copulas, Reboredo et al. (2016) investigated the downside and upside risk spillovers between exchange rates and equity prices. Tsuji (2016) empirically exhibited that, in predicting the US equity market downside risk, US VIX did not outperform the volatility forecasts of S\&P 500, which were derived from EGARCH and TGARCH models. Min and Kim (2016) investigated whether the time-variations of momentum strategies' profitability have a relationship with the variations in macroeconomic conditions, and they found that momentum strategies exposed investors to greater downside risk in financial markets.

Sukcharoen and Leatham (2017) empirically examined the effectiveness of hedging downside risk of oil refineries by applying vine copulas. The empirical results of this study suggested that the D-vine copula model was a safe and good choice in managing the downside risk as to oil refineries. Tsuji (2017b) investigated the forecast power of the previous day's US VIX for large price drops in the Tokyo Stock Price Index (TOPIX) in Japan, and this study exhibited that the previous day's US VIX had statistically significant forecast power for large price declines in the TOPIX in Japan. Further, Xiaoye (2018) investigated the downside and upside risk spillovers from China to Asian equity markets by applying a CoVaR-copula approach.

Moreover, Farago and Tédongap (2018) researched by focusing on downside risk in asset pricing framework, and they found three priced disappointment-related factors in the US; namely, (i) a downstate factor, (ii) a market downside factor, and (iii) a volatility downside factor. Tsuji (2018a) analyzed return transmission and volatility spillovers between oil futures and international oil equities, and interpreted the clarified asymmetric spillovers between them were related to downside risk in the international oil and equity markets. Finally, using the data of 20 global currencies against the US dollar, Chuliá et al. (2018) investigated the currency downside risk, liquidity, and financial stability by estimating volatility- and quantile-based spillovers across the 20 currencies against the US dollar.

As the above recent literature review shows, we understand that downside risk is one of the most significant and appealing research topics in the fields of business, economics, and finance. Hence in this study, focusing on downside risk in the Southern and Western European equity markets, we quantitatively examine whether and how UK VIX predict downside risk in other European equity markets of France, Italy, Spain, and Portugal.

\section{Data and Variables}

This section explains our data and variables. In this study, DUKVIX denotes the first difference series of the VIX as to FTSE100 in the UK; DFRA denotes the first difference series of the French equity price index, CAC40; DITA denotes the first difference series of the Italian equity price index, FTSE MIB; DSPN denotes the first difference series of the Spanish equity price index, IBEX35; and DPORT denotes the first difference series of the Portuguese equity price index, PSI ALL-SHARE.

All price data are from Thomson Reuters, and the sample period is from May 14, 2004 to August 2, 2018 for price series, and the period from May 17, 2004 to August 2, 2018 is for all the first price difference (i.e., price change) series. Figure 1 displays the daily time-series evolution of all the above four equity prices with the UK VIX, and Figure 2 shows all the above first difference series of the four equity price indices with the first difference series of the UK VIX.

In this study, as above, we use not return series but price change series because price changes are more important than return series in the context of risk management of asset prices as they are used in the Value-at-Risk (VaR) computations. As in VaR calculations, we focus on the left-tail quantiles of asset price changes in this study. Thus, our use of the quantile regressions applied to price change data in this paper is suitable from the viewpoint of the downside risk evaluation, which is the focus of this study.

Table 1 shows the descriptive statistics for the first difference series of the four European equity price indices 
and the first difference series of the UK VIX. This table suggests that the skewness value of DUKVIX is positive, while the skewness values of DFRA, DITA, DSPN, and DPORT are all negative. Further, Table 1 also shows that the kurtosis of DUKVIX is especially high, and the kurtosis values of DFRA, DITA, DSPN, and DPORT are also higher than that of normal distributions. In addition, Figure 1 indicates that when the UK VIX largely increases, the equity prices of France, Italy, Spain, and Portugal sharply drop. Further, Figure 2 shows that when the volatility of the UK VIX changes largely increases, the volatilities of the changes in equity prices of France, Italy, Spain, and Portugal also sharply increases.

\section{Methodology}

This section documents our investigating methodology. In this study, we employ the following quantile regression model (1):

$$
Q_{t}=\xi_{0}+\xi_{1} D U K V I X_{t-k}+v_{t} .
$$

In the above model (1), $Q_{t}$ denotes the specified quantile of the distribution of DFRA, DITA, DSPN, or DPORT. In our analyses, we use 0.01 quantile, 0.015 quantile, and 0.02 quantile in order to capture the large downside risk of the four European equity indices. Further, DUKVIX $t_{t-k}$ denotes the $k$ th lag variable of the daily first difference series of the VIX as to FTSE100, and we use $k=1, \ldots, 5$.

Hence, using model (1), we can test the predictive power and predictive speed of the UK VIX changes as to the $1 \%$ left-tail, $1.5 \%$ left-tail, and $2 \%$ left-tail downside risk of the distributions for price changes in other European equity indices of France, Italy, Spain, and Portugal. As we noted, the quantile regressions are suitable for examining the left-tail downside risk of equity price changes more directly and effectively.

\section{Empirical Results}

This section documents our main results. As noted, we derive our results by using price change series because price changes are more important than return series in the context of asset price downside risk evaluations. In fact, in VaR calculations, asset price changes are often used. Hence, we focus on the left-tail quantiles of equity price changes in this study. Table 2 exhibits the estimation results of our quantile regression model (1), and this table shows the predictive power and predictive speed of the UK VIX for the large price declines in other European equity markets. First, Panel A of Table 2 indicates that the second and third lags of the changes in the UK VIX predict the $0.01,0.015$, and 0.02 quantile downside risk for the French equity market. This means that the turmoil of the UK equity market predicts the $1 \%, 1.5 \%$, and $2 \%$ left-tail downside risk for the French equity market, and the increasing fear in the UK equity market spills over to the French equity market in two or three days.

Table 1. Descriptive statistics of price changes in European equity indices and UK VIX changes

\begin{tabular}{|c|c|c|c|}
\hline & DUKVIX & DFRA & DITA \\
\hline Mean & -0.0014 & 0.5009 & -1.5837 \\
\hline Median & -0.0200 & 0.8100 & 6.2800 \\
\hline Maximum & 23.3000 & 367.0100 & 2333.5900 \\
\hline Minimum & -14.1400 & -368.7700 & -2242.3600 \\
\hline Standard deviation & 1.5843 & 53.3033 & 322.7287 \\
\hline Skewness & 1.1548 & -0.1966 & -0.2711 \\
\hline Kurtosis & 28.2022 & 8.0400 & 7.8981 \\
\hline & \multicolumn{2}{|c|}{ DSPN } & DPORT \\
\hline Mean & \multicolumn{2}{|c|}{0.5173} & -0.0138 \\
\hline Median & \multicolumn{2}{|c|}{3.8000} & 0.3300 \\
\hline Maximum & \multicolumn{2}{|c|}{1305.8000} & 133.2500 \\
\hline Minimum & \multicolumn{2}{|c|}{-1097.6000} & -161.5100 \\
\hline Standard deviation & \multicolumn{2}{|c|}{139.8906} & 17.2408 \\
\hline Skewness & \multicolumn{2}{|c|}{-0.1674} & -0.5287 \\
\hline Kurtosis & \multicolumn{2}{|c|}{10.5293} & 12.2198 \\
\hline
\end{tabular}

Note. DUKVIX denotes the first difference series of the VIX as to FTSE100; DFRA denotes the first price difference series of CAC40; DITA denotes those of FTSE MIB; DSPN denotes those of IBEX35; and DPORT denotes those of PSI ALL-SHARE. All observations for the five time-series are 3,709. 
Panel A. France

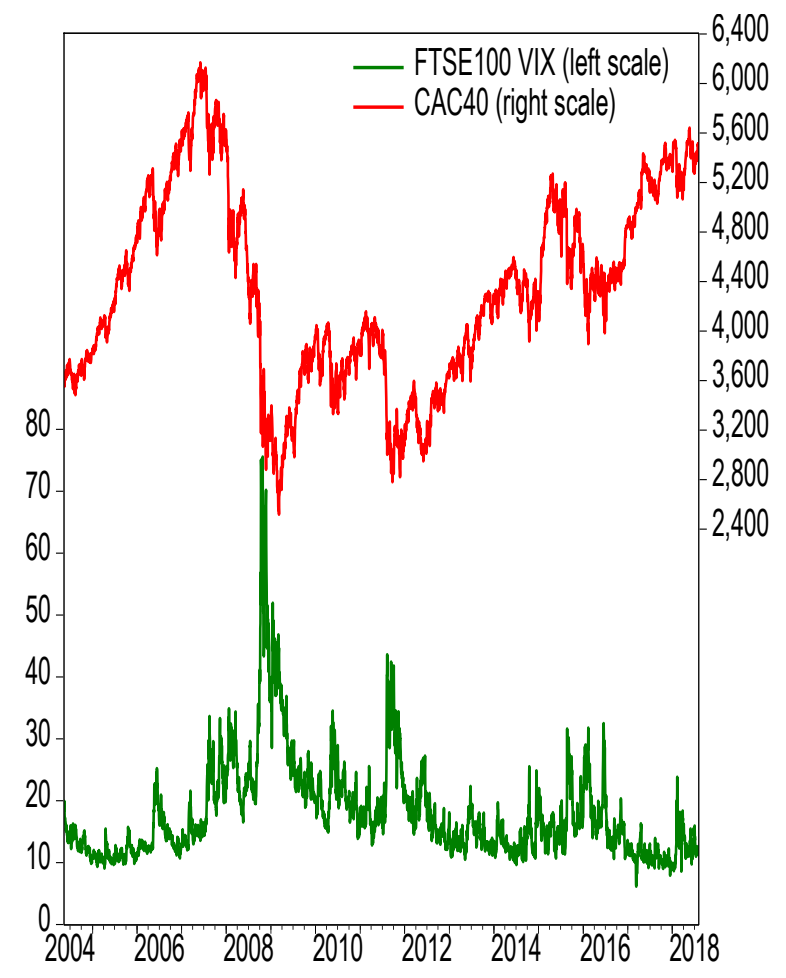

Panel C. Spain

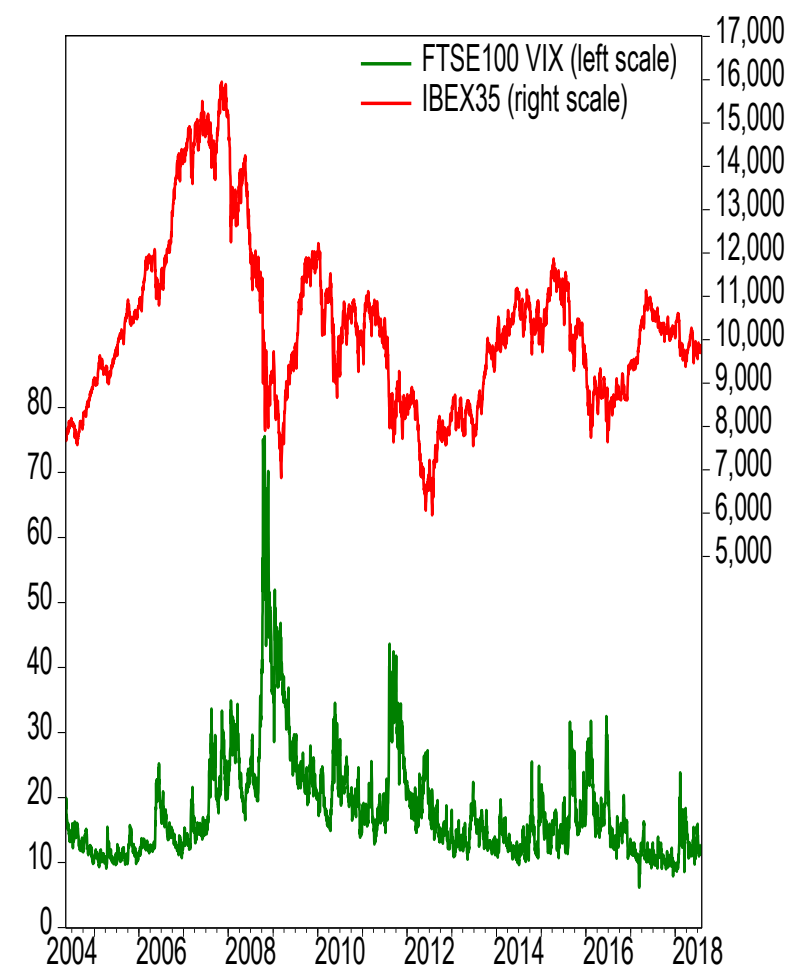

Panel B. Italy

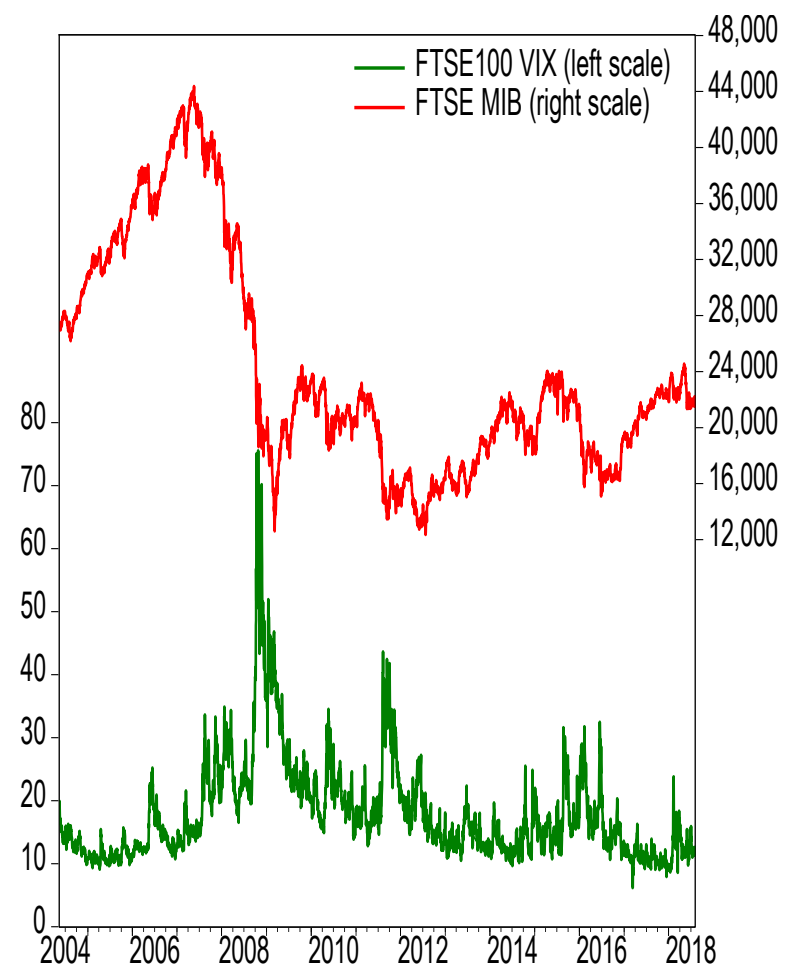

Panel D. Portugal

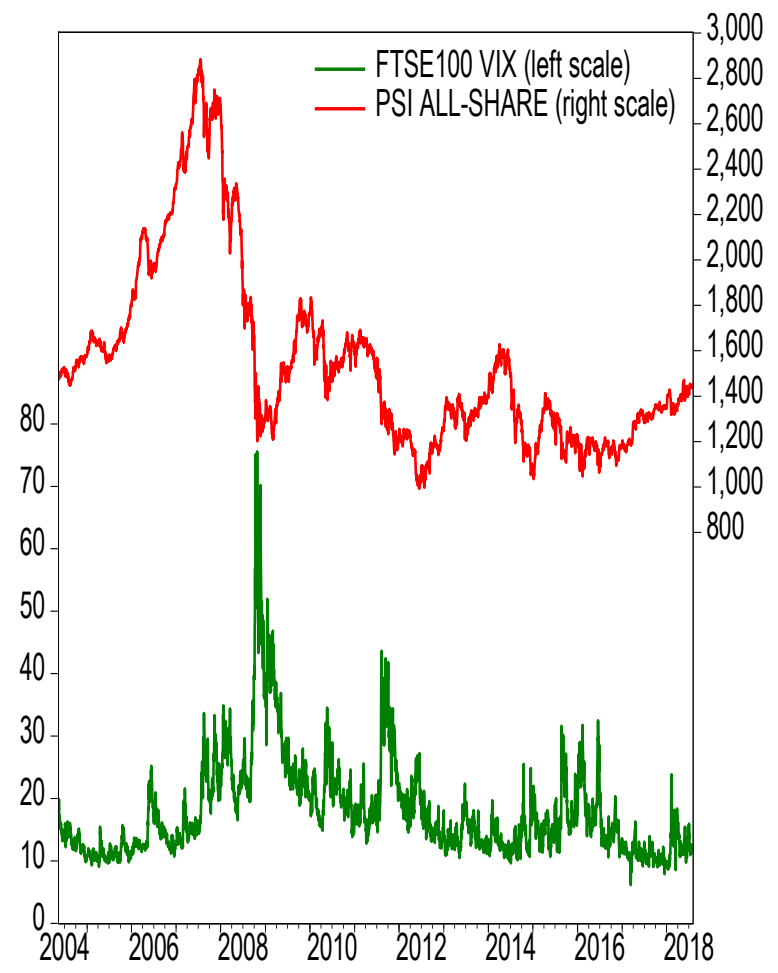

Figure 1. Dynamic time-series price evolution of European countries' equity indices with the VIX in the UK: From May 14, 2004 to August 2, 2018 
Panel A. France

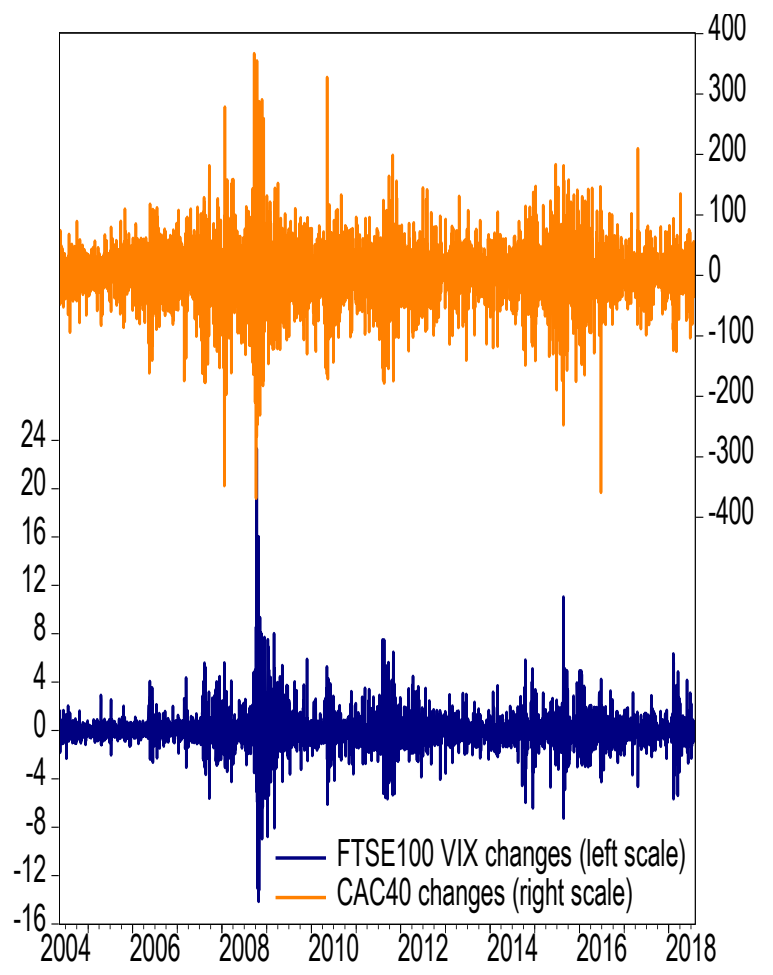

Panel C. Spain

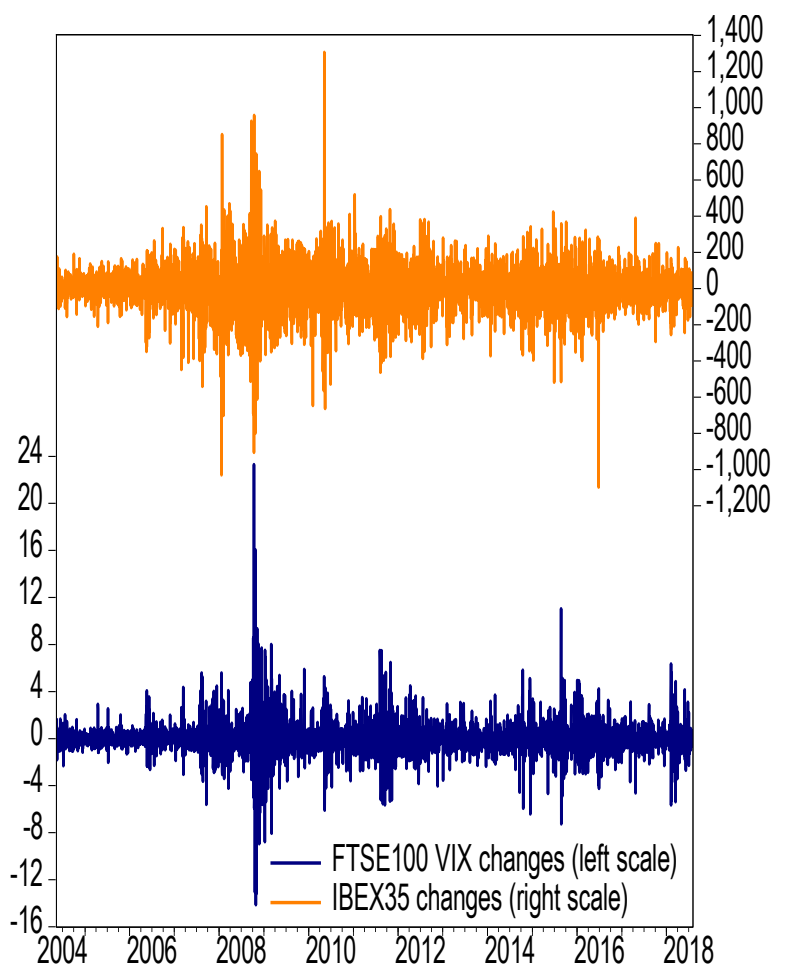

Panel B. Italy

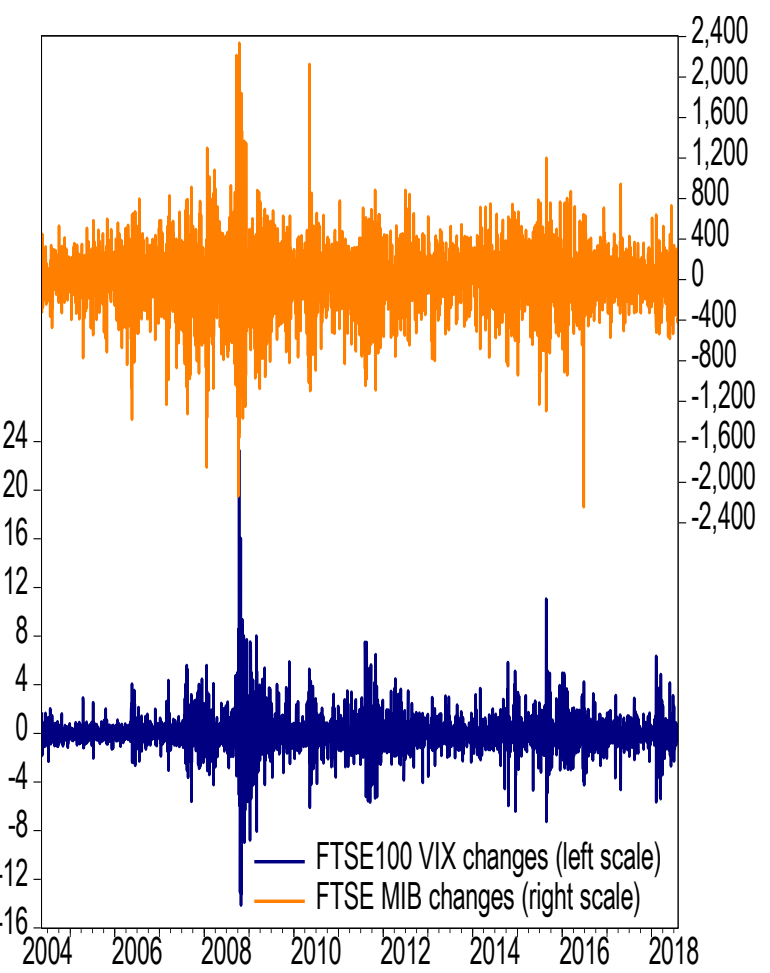

Panel D. Portugal

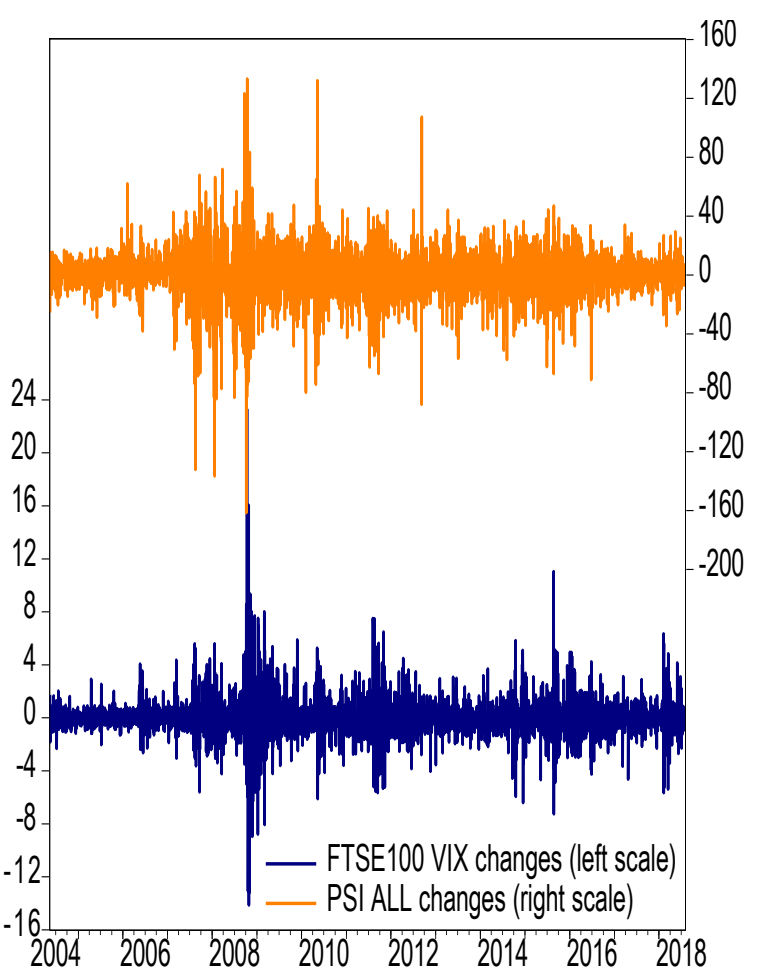

Figure 2. Dynamic time-series evolution of price changes in European countries' equity indices with UK VIX changes: From May 17, 2004 to August 2, 2018 
Table 2. Predictive speed of the UK VIX for the large price declines in equity indices of other European countries: Results of quantile regressions

\begin{tabular}{|c|c|c|c|c|c|c|}
\hline \multicolumn{7}{|l|}{ Panel A. France } \\
\hline & \multicolumn{2}{|c|}{0.01 quantile } & \multicolumn{2}{|c|}{0.015 quantile } & \multicolumn{2}{|c|}{0.02 quantile } \\
\hline & Coefficient & $p$-value & Coefficient & $p$-value & Coefficient & $p$-value \\
\hline Constant & $-146.5005 * * *$ & 0.0000 & $-131.1324 * * *$ & 0.0000 & $-120.7339 * * *$ & 0.0000 \\
\hline DUKVIX $(-1)$ & 3.3113 & 0.3804 & 0.2997 & 0.8528 & 1.3997 & 0.1880 \\
\hline DUKVIX $(-2)$ & -3.3968 & 0.1440 & $-2.7142 * *$ & 0.0107 & $-2.1391 * * *$ & 0.0037 \\
\hline DUKVIX(-3) & $-3.7722 * *$ & 0.0398 & $-5.3453 * * *$ & 0.0016 & $-5.5420 * * *$ & 0.0000 \\
\hline DUKVIX(-4) & -1.4074 & 0.7506 & -2.1114 & 0.3552 & -1.6458 & 0.2180 \\
\hline DUKVIX $(-5)$ & 2.3319 & 0.4604 & 2.8743 & 0.1176 & 1.5837 & 0.1441 \\
\hline
\end{tabular}

Panel B. Italy

0.01 quantile

0.015 quantile

0.02 quantile

\begin{tabular}{lcccccc}
\hline & Coefficient & $p$-value & Coefficient & $p$-value & Coefficient & $p$-value \\
\hline Constant & $-916.9733^{* * * *}$ & 0.0000 & $-791.8599 * * *$ & 0.0000 & $-747.5550 * * *$ & 0.0000 \\
DUKVIX(-1) & $29.6605 * * *$ & 0.0029 & 9.2034 & 0.3299 & 2.3928 & 0.6868 \\
DUKVIX(-2) & $-33.8504 * * *$ & 0.0011 & -11.8987 & 0.5985 & -19.6509 & 0.1271 \\
DUKVIX(-3) & -13.4432 & 0.1668 & $-27.8245^{* * *}$ & 0.0000 & $-29.4966 * * *$ & 0.0100 \\
DUKVIX(-4) & $-17.1099 * * *$ & 0.0059 & $-27.1027 * * *$ & 0.0010 & $-32.2428 * * *$ & 0.0000 \\
DUKVIX(-5) & $31.6342 * * *$ & 0.0000 & $16.2099 *$ & 0.0594 & 12.8975 & 0.1079
\end{tabular}

Panel C. Spain

\begin{tabular}{lcccccc}
\hline & \multicolumn{2}{c}{0.01 quantile } & \multicolumn{2}{c}{0.015 quantile } & \multicolumn{2}{c}{0.02 quantile } \\
\hline & Coefficient & $p$-value & Coefficient & $p$-value & Coefficient & $p$-value \\
\hline Constant & $-384.0946^{* * *}$ & 0.0000 & $-339.6576^{* * *}$ & 0.0000 & $-315.0487^{* * *}$ & 0.0000 \\
DUKVIX(-1) & $4.9010^{* *}$ & 0.0304 & 0.8935 & 0.7561 & -0.2470 & 0.9110 \\
DUKVIX(-2) & -3.9899 & 0.5365 & 1.0542 & 0.8192 & -4.7069 & 0.1889 \\
DUKVIX(-3) & $-6.1510^{* * *}$ & 0.0031 & $-7.9787 * * *$ & 0.0000 & $-10.4921 * * *$ & 0.0000 \\
DUKVIX(-4) & -2.4303 & 0.5536 & -2.3766 & 0.3492 & $-5.0431^{* * *}$ & 0.0085 \\
DUKVIX(-5) & 2.7151 & 0.2348 & 0.2751 & 0.9227 & 1.2125 & 0.6315 \\
\hline
\end{tabular}

Panel D. Portugal

\begin{tabular}{lcccccc}
\hline & \multicolumn{2}{c}{0.01 quantile } & \multicolumn{2}{c}{0.015 quantile } & \multicolumn{2}{c}{0.02 quantile } \\
\hline & Coefficient & $p$-value & Coefficient & $p$-value & Coefficient & $p$-value \\
\hline Constant & $-50.7222^{* * * *}$ & 0.0000 & $-45.4806^{* * * *}$ & 0.0000 & $-40.6466^{* * *}$ & 0.0000 \\
DUKVIX $(-1)$ & 0.6325 & 0.1418 & 0.0985 & 0.8830 & -0.1826 & 0.8051 \\
DUKVIX(-2) & 0.3387 & 0.7326 & -0.4838 & 0.4559 & -0.9485 & 0.2670 \\
DUKVIX(-3) & -0.2936 & 0.7271 & $-1.2586^{*}$ & 0.0991 & -1.8222 & 0.1122 \\
DUKVIX(-4) & $-0.7613^{* * *}$ & 0.0067 & $-0.9961^{*}$ & 0.0939 & -0.4897 & 0.5126 \\
DUKVIX(-5) & 0.1938 & 0.8733 & 0.3082 & 0.8513 & 0.8762 & 0.5076 \\
\hline
\end{tabular}

Note. In Panel A, the dependent variable is DFRA; in Panel B, the dependent variable is DITA; in Panel C, that is DSPN; and in Panel D, that is DPORT. In this table, DUKVIX $(-k)$ denotes the $k$ th lag variable of the daily first difference series of the VIX as to FTSE100. ***, **, and * means the statistical significance at the $1 \%$, 5\%, and $10 \%$ levels, respectively. 
Second, Panel B of Table 2 suggests that the second, third, and fourth lags of the changes in the UK VIX predict the $0.01,0.015$, and 0.02 quantile downside risk for the Italian equity market. This indicates that the turmoil of the UK equity market predicts the $1 \%, 1.5 \%$, and $2 \%$ left-tail downside risk for the Italian equity market, and the increasing fear in the UK equity market spills over to the Italian equity market in two to four days. Third, Panel $\mathrm{C}$ of Table 2 indicates that the third and/or fourth lags of the changes in the UK VIX predict the $0.01,0.015$, and 0.02 quantile downside risk for the Spanish equity market. This means that the turmoil of the UK equity market predicts the $1 \%, 1.5 \%$, and $2 \%$ left-tail downside risk for the Spanish equity market, and the increasing fear in the UK equity market spills over to the Spanish equity market in three or four days. Fourth, Panel D of Table 2 suggests that the third and/or fourth lags of the changes in the UK VIX predict the 0.01 and 0.015 quantile downside risk for the Portuguese equity market. This suggests that the turmoil of the UK equity market predicts the $1 \%$ and $1.5 \%$ left-tail downside risk for the Portuguese equity market, and the increasing fear in the UK equity market spills over to the Portuguese equity market in three or four days.

In addition, Panels A to D of Table 2 indicate that in general, the first lags of the changes in the UK VIX do not predict the $0.01,0.015$, or 0.02 quantile downside risk for other four European equity markets, and the coefficients of the first lags of the UK VIX changes take positive signs weirdly in general. We interpret that this is because the UK VIX includes the information as to downside risk in other European equity markets very quickly, and as a result, the first lags of the UK VIX changes show little linkages with the downside risk for other four European equity markets.

However, as above, interestingly, all our empirical results from effective quantile regressions show that the two to four days before, the changes in the UK VIX can forecast the downside risk for other European equity markets investigated in this study. We note that looking at the statistically significant lags of the UK VIX changes in Panels A to D in Table 2, it is also understood that after the increases of the UK VIX, the equity prices in France firstly drop, and then those in Italy decline. After that, the equity prices in Spain decline, and then those in Portugal drop. Therefore, our quantile regression analyses also reveal that the predictive and spillover speed of the UK VIX changes as to the downside risk in other four European equity markets slightly differ with countries. Overall, as we demonstrated above, the UK VIX have statistically significant forecast power for sharp price drops in other European equity markets of France, Italy, Spain, and Portugal.

\section{Summary and Conclusions}

In the fields of business, economics, and finance, downside risk in financial markets is highly crucial, and recently, on the back of globalizing and tightening financial markets, the research of downside risk becomes more important. More concretely, how does the downside risk in international equity markets spill over? Further, how is the speed of downside risk spillovers in international equity markets? In order to answer these research questions, using the time-series data of the UK VIX and other four European equity indices, and applying quantile regressions, this study has investigated the predictive power and predictive speed of the UK VIX for the future sharp price drops in the equity markets of France, Italy, Spain, and Portugal. Our empirical examinations derived the following findings.

First, (1) the second and third lags of the changes in the UK VIX predict the $0.01,0.015$, and 0.02 quantile downside risk for the French equity market. Next, (2) the second, third, and fourth lags of the changes in the UK VIX predict the $0.01,0.015$, and 0.02 quantile downside risk for the Italian equity market. Third, (3) the third and/or fourth lags of the changes in the UK VIX predict the $0.01,0.015$, and 0.02 quantile downside risk for the Spanish equity market. Fourth, (4) the third and/or fourth lags of the changes in the UK VIX predict the 0.01 and 0.015 quantile downside risk for the Portuguese equity market. Finally, (5) as to the predictive and spillover speed of downside risk, after the increases of the UK VIX, the equity prices in France firstly drop, and then those in Italy decline. After that, the equity prices in Spain decline, and then those in Portugal drop. Therefore, our quantile regression analyses also revealed that the predictive and spillover speed of the UK VIX as to downside risk in other four European equity markets slightly differ with countries.

In addition, our empirical results can be interpreted as follows. First, (1) the downside risk in European equity markets comoves. This interpretation is quite interesting and important, and we also consider that such downside risk comovements may relate to the psychology of equity markets because VIX is known as a fear gauge. Second, (2) we understand that there are downside risk spillovers between the UK and other European equity markets, and this can be interpreted that the spillovers of asset price evolutions between international equity markets shall be asymmetric (This context of spillovers is analyzed by Tsuji (2018a, 2018b), for example.). These two viewpoints are highly important and useful for further considerations of the issues related to international financial market linkages and interactions. This kind of further work is one of our future tasks. 


\section{Acknowledgments}

The author is particularly grateful to the repeated and courteous invitation from the journal to write to this journal. The author also appreciates the Japan Society for the Promotion of Science Grant-in-Aid for Scientific Research and the Chuo University Personal Research Grant for their generous financial assistance to this research. In addition, the author thanks an editor and three anonymous referees for their supportive and constructive comments on this paper. Furthermore, the author also thanks Kevin Duran for his kind editorial assistance to my paper. Finally, the author deeply thanks all the Editors of this journal for their care and kind attention on my paper.

\section{References}

Bernstein, S., Colonnelli, E., Giroud, X., \& Iverson, B. (2018). Bankruptcy spillovers. Journal of Financial Economics, forthcoming.

Chuliá, H., Fernández, J., \& Uribe, J. M. (2018). Currency downside risk, liquidity, and financial stability. Journal of International Money and Finance, 89, 83-102. https://doi.org/10.1016/j.jimonfin.2018.09.009

Farago, A., \& Tédongap, R. (2018). Downside risks and the cross-section of asset returns. Journal of Financial Economics, 129, 69-86. https://doi.org/10.1016/j.jfineco.2018.03.010

Galsband, V. (2012). Downside risk of international stock returns. Journal of Banking \& Finance, 36, 2379-2388. http://dx.doi.org/10.1016/j.jbankfin.2012.04.019

Hilal, S., Poon, S. H., \& Tawn, J. (2011). Hedging the black swan: Conditional heteroskedasticity and tail dependence in S\&P500 and VIX. Journal of Banking \& Finance, 35, 2374-2387. https://doi.org/10.1016/j.jbankfin.2011.01.035

Min, B. K., \& Kim, T. S. (2016). Momentum and downside risk. Journal of Banking \& Finance, 72, S104-S118. http://dx.doi.org/10.1016/j.jbankfin.2016.04.005

Reboredo, J. C., \& Rivera-Castro, M. A. (2014). Gold and exchange rates: Downside risk and hedging at different investment horizons. International Review of Economics and Finance, 34, 267-279. http://dx.doi.org/10.1016/j.iref.2014.07.005

Reboredo, J. C., Rivera-Castro, M. A., \& Ugolini, A. (2016). Downside and upside risk spillovers between exchange rates and stock prices. Journal of Banking \& Finance, 62, 76-96. http://dx.doi.org/10.1016/j.jbankfin.2015.10.011

Sukcharoen, K., \& Leatham, D. J. (2017). Hedging downside risk of oil refineries: A vine copula approach. Energy Economics, 66, 493-507. http://dx.doi.org/10.1016/j.eneco.2017.07.012

Tsuji, C. (2016). Does the fear gauge predict downside risk more accurately than econometric models? Evidence from the US stock market. Cogent Economics \& Finance, 4: 1220711, 1-42. http://dx.doi.org/ 10.1080/23322039.2016.1220711

Tsuji, C. (2017a). Forecasting large price declines of the Nikkei using the S\&P 500 implied volatility. International Journal of Business Administration, 8, 58-64. http://dx.doi.org/10.5430/ijba.v8n1p58

Tsuji, C. (2017b). Does the CBOE volatility index predict downside risk at the Tokyo stock exchange? International Business Research, 10, 1-7. http://dx.doi.org/10.5539/ibr.v10n3p1

Tsuji, C. (2018a). Return transmission and asymmetric volatility spillovers between oil futures and oil equities: New DCC-MEGARCH analyses. Economic Modelling, 74, 167-185. https://doi.org/10.1016/j.econmod.2018.05.007

Tsuji, C. (2018b). New DCC analyses of return transmission, volatility spillovers, and optimal hedging among oil futures and oil equities in oil-producing countries. Applied Energy, forthcoming.

Xiaoye, J. (2018). Downside and upside risk spillovers from China to Asian stock markets: A CoVaR-copula approach. Finance Research Letters, 25, 202-212. http://dx.doi.org/10.1016/j.frl.2017.10.027

\section{Copyrights}

Copyright for this article is retained by the author(s), with first publication rights granted to the journal.

This is an open-access article distributed under the terms and conditions of the Creative Commons Attribution license (http://creativecommons.org/licenses/by/4.0/). 